\title{
Clinical Predictors of Atheroma Progression Despite Optimal Glycemic Control in Early-Stage Diabetic Patients with Coronary Artery Disease: Insight from the DIANA Study
}

\author{
Yu Kataoka ${ }^{1}$, Satoshi Yasuda ${ }^{2}$, Yoshihiro Miyamoto $^{3}$, Kazuhiro Sase $^{4}$, Masami Kosuge ${ }^{5}$, Kazuo Kimura ${ }^{5}$, \\ Yasunao Yoshimasa $^{6}$ and Shunichi Miyazaki ${ }^{7}$ on behalf of the DIANA study investigators
}

\author{
${ }^{1}$ South Australian Health \& Medical Research Institute, Adelaide, SA, Australia \\ ${ }^{2}$ Department of Cardiovascular Medicine, National Cerebral and Cardiovascular Center, Osaka, Japan \\ ${ }^{3}$ Department of Preventive Cardiology, National Cerebral and Cardiovascular Center, Osaka, Japan \\ ${ }^{4}$ Department of Clinical Pharmacology, Juntendo University School of Medicine, Tokyo, Japan \\ ${ }^{5}$ Division of Cardiology, Yokohama City University Medical Center, Yokohama, Japan \\ ${ }^{6}$ Yoshimasa Clinic, Osaka, Japan \\ ${ }^{7}$ Division of Cardiology, Department of Internal Medicine, Kinki University School of Medicine, Osaka, Japan
}

\begin{abstract}
Aim: In the DIANA (DIAbetes and diffuse coronary NArrowing) study, which evaluated the impact of glucose-lowering therapy in early-stage diabetics with coronary artery disease (CAD), optimal glycemic control resulted in reduced disease progression on angiography. However, despite having a favorable glycemic status, some patients continued to exhibit disease progression. Factors associated with disease progression despite optimal glucose control remain to be elucidated. We sought to investigate clinical characteristics associated with substantial atheroma progression in early-stage diabetic patients with CAD who achieve favorable glycemic control.

Methods: The DIANA study is a prospective randomized trial comparing the effects of lifestyle intervention and treatment with voglibose or nateglinide on disease progression on angiography in 302 CAD patients with impaired glucose tolerance/newly diagnosed diabetes. Of these patients, 137 CAD subjects who achieved optimal glycemic control were stratified according to the presence of disease progression on angiography: progressors $(n=64)$ and non-progressors $(n=73)$. Serial coronary angiography studies and quantitative coronary angiography analyses were conducted to evaluate disease progression. A multivariate analysis was performed to elucidate factors associated with disease progression.

Results: Despite the achievement of optimal glycemic control, atheroma progression was observed in $46 \%$ of the study subjects. The progressors exhibited lower decreases in systolic blood pressure (SBP: $p=0.007$ ) and reduced baseline total lesion lengths (TLL: $p=0.01$ ). The multivariate analysis demonstrated that a greater increase in SBP $(p=0.006)$, treatment without statins $(p=0.03)$ and the baseline TLL $(p=0.007)$ were independently associated with disease progression.

Conclusions: Residual risk factors contribute to the progression of coronary atherosclerosis in earlystage diabetics who exhibit improvements in their glycemic status. The present findings underscore the need to intensively modify multiple risk factors during the early diabetic phase in order to prevent atheroma progression.
\end{abstract}

J Atheroscler Thromb, 2014; 21:509-518.

Key words: Early-stage diabetes, Glycemic control, Residual risk factors, Disease progression

\section{Introduction}

In association with the global spread of abdominal adiposity, the prevalence of type 2 diabetes melli- tus (DM) has increased worldwide ${ }^{1)}$. Diabetic patients are characterized by the presence of an accelerated progressive atheroma burden with a markedly increased incidence of adverse cardiovascular events ${ }^{2-5}$. Various 
epidemiological studies have reported that vascular risks are increased in pre- or newly diagnosed diabetic patients ${ }^{6-9)}$. Other imaging studies have also identified the presence of inflamed and extensive disease substrates in patients with impaired glucose tolerance (IGT) ${ }^{10-12)}$. These observations indicate that earlystage diabetic patients constitute an important therapeutic target for the prevention of future cardiovascular events.

Recently, the DIANA (Diabetes and Diffuse Coronary Narrowing) study, a prospective randomized trial evaluating the effects of glucose-lowering therapy in early-stage diabetics with coronary artery disease (CAD), demonstrated that favorable glycemic control is associated with reduced disease progression on angiography ${ }^{13)}$. These results support the benefits of implementing glucose control strategies to prevent disease progression in the early stage of diabetes. However, not all patients with favorable glycemic control exhibit reduced progression of coronary atherosclerosis. Moreover, residual risk factors associated with atheroma progression despite the achievement of favorable glycemic control have not yet been characterized. Therefore, in the current study, we sought to investigate clinical characteristics correlated with substantial atheroma progression in early-stage diabetic patients who achieve favorable glycemic control. This subanalysis provided insight regarding important therapeutic targets contributing to the natural history of coronary atherosclerosis progression in early-stage diabetic patients with CAD.

\section{Methods}

\section{Design Overview}

The details of the DIANA study have been previously described ${ }^{13)}$. Briefly, this study was a prospective randomized open-label blinded assessment of an end point trial conducted at 12 institutes in Japan (Trial Registration: UMIN-CTRID\#0000107). A total of 302 angiographic CAD patients with both IGT or newly diagnosed DM and a glycosylated hemoglobin (HbA1c) level of $<6.5 \%$ (6.9\% NGSP $48 \mathrm{mmol} / \mathrm{mol})$ were enrolled. The patients were randomly assigned to receive lifestyle intervention $(n=101), 0.9 \mathrm{mg}$ of voglibose $(n=100)$ or $180 \mathrm{mg}$ of nateglinide $(n=101)$

Address for correspondence: Shunichi Miyazaki, Division of Cardiology, Department of Internal Medicine, Kinki University School of Medicine, 377-2, Ohno-Higasgi, Osakasayama, Osaka, 589-8511, Japan

E-mail: smiyazak@med.kindai.ac.jp

Received: August 25, 2013

Accepted for publication: November 17, 2013 for one year. 75-g oral glucose tolerance tests were performed at baseline and at one year to assess serial changes in the glycemic status. Coronary atherosclerotic changes were evaluated on coronary angiography using a quantitative coronary arteriography (QCA) analysis at baseline and one year, as previously published in detail ${ }^{11,13,14)}$. In brief, diseased lesions were defined as major coronary segments narrowed to a diameter of $\leq 1.5 \mathrm{~mm}$. The target lesion length (TLL) was determined by summing the lengths of all diseased lesions in three major coronary arteries. The percent change in TLL was calculated using the following formula for the assessment of angiographic disease progression:

Percent change in TLL $(\%)=[($ TLL at one year - TLL at baseline $) /($ TLL at baseline $)] \times 100$

The percent change in TLL was normally distributed, as shown in the $p$-value of the Shapiro-Wilk test $(p=0.34>$ an alpha level of 0.05$)$. The QCA data were assessed by two experienced cardiologists blinded to the subjects' glucose tolerance status and assigned group. The inter- and intraobserver correlation coefficients and percent error of the TLL measurements were 0.93 and $7.4 \pm 5.9 \%$ and 0.98 and $3.9 \pm 2.6 \%$, respectively. The DIANA study was approved by each participating center's institutional review board.

\section{Study Subjects}

This post hoc analysis included patients who exhibited an improvement in their glycemic status at one year regardless of the assigned therapy in the DIANA study. A total of 137 patients who exhibited an improvement in their glycemic status were stratified into two groups according to the presence of disease progression: progressors $(n=64)$ and non-progressors $(n=73)$.

\section{Definitions of an Improvement in the Glycemic Status and Disease Progression}

An improvement in the glycemic status was defined as reversion of the glycemic status on a 75-g oral glucose tolerance test from IGT to normal glucose tolerance or from DM to IGT/normal glucose tolerance. The World Health Organization criteria were used to classify the 75-g oral glucose tolerance test results ${ }^{15)}$. We defined disease progression as an absolute change in TLL greater than $0 \mathrm{~mm}$.

\section{Statistical Analysis}

The data for the clinical characteristics and use of baseline medications are expressed as the mean \pm $\mathrm{SD}$ for continuous variables and the percentage for 
Table 1. Baseline Clinical Characteristics and Use of Medical Therapies in the Progressors and Non-progressors

\begin{tabular}{|c|c|c|c|}
\hline & $\begin{array}{l}\text { Non-progressor } \\
\quad(n=73)\end{array}$ & $\begin{array}{l}\text { Progressor } \\
\quad(n=64)\end{array}$ & $p$-value \\
\hline Age (years) & $64.4 \pm 9.3$ & $62.8 \pm 9.8$ & 0.36 \\
\hline Female (\%) & 19.0 & 8.9 & 0.11 \\
\hline IGT (\%) & 52.2 & 44.6 & 0.40 \\
\hline $\mathrm{DM}(\%)$ & 47.8 & 55.4 & 0.54 \\
\hline Hypertension (\%) & 85.6 & 86.1 & 0.86 \\
\hline Hypercholesterolemia (\%) & 65.0 & 68.1 & 0.71 \\
\hline Current smoker (\%) & 27.1 & 28.5 & 0.82 \\
\hline History of MI (\%) & 7.9 & 19.6 & 0.06 \\
\hline PAD (\%) & 3.1 & 3.5 & 0.90 \\
\hline \multicolumn{4}{|c|}{ Assigned therapy in the DIANA study } \\
\hline Life-style intervention (\%) & 26.9 & 41.0 & 0.10 \\
\hline Voglibose (\%) & 33.3 & 35.7 & 0.78 \\
\hline Nateglinide (\%) & 39.6 & 23.2 & 0.06 \\
\hline \multicolumn{4}{|l|}{ Medication } \\
\hline \multicolumn{4}{|l|}{ Statins } \\
\hline baseline (\%) & 65.0 & 62.5 & 0.77 \\
\hline follow up (\%) & 85.7 & 76.1 & 0.19 \\
\hline \multicolumn{4}{|l|}{ Aspirin } \\
\hline baseline (\%) & 100.0 & 100.0 & 1.00 \\
\hline follow up (\%) & 100.0 & 100.0 & 1.00 \\
\hline \multicolumn{4}{|l|}{ Beta-blocker } \\
\hline baseline (\%) & 66.6 & 69.6 & 0.73 \\
\hline follow up (\%) & 70.8 & 63.1 & 0.26 \\
\hline \multicolumn{4}{|l|}{ Calcium channel blocker } \\
\hline baseline (\%) & 30.1 & 25.0 & 0.53 \\
\hline follow up (\%) & 33.3 & 33.9 & 0.94 \\
\hline \multicolumn{4}{|l|}{ ACE-I } \\
\hline baseline (\%) & 25.3 & 37.5 & 0.15 \\
\hline follow up (\%) & 22.2 & 33.9 & 0.15 \\
\hline \multicolumn{4}{|l|}{$\mathrm{ARB}$} \\
\hline baseline (\%) & 42.8 & 28.5 & 0.10 \\
\hline follow up (\%) & 50.7 & 39.2 & 0.21 \\
\hline
\end{tabular}

ACE- $\mathrm{I}=$ angiotensin $I I$ co-enzyme, $\mathrm{ARB}=$ angiotensin $I I$ receptor blocker, DIANA = DIAbetes and diffuse coronary Narrowing, $\mathrm{DM}=$ diabetes mellitus, $\mathrm{IGT}=$ impaired glucose tolerance, $\mathrm{MI}=$ myocardial infarction, $\mathrm{PAD}=$ peripheral arterial disease

categorical variables. The subjects' baseline demographics, medical histories, baseline and follow-up biochemical data (glycemic parameters, lipid profiles, high-sensitivity C-reactive protein, adiponectin and blood pressure) and QCA measurements were compared between the groups. Two-sample $t$-tests were performed to assess normally distributed continuous variables, the Wilcoxon rank-sum test was used to assess non-normally distributed continuous variables and the chi-square test was conducted to evaluate categorical variables. Univariate and multivariate analyses were performed to investigate clinical factors contributing to substantial atheroma progression. For the univariate analysis, the following clinical variables and risk factors were regarded as covariates: age, glycemic status at baseline, \% change in glucose, insulin, lipids, blood pressure, BMI, adiponectin and hs-CRP, baseline TLL and the use of cardiovascular medications and lifestyle interventions. We performed a multivariate logistic regression analysis based on the results of the univariate analysis. Model 1 of the multivariate analysis included all covariates with a $p$-value of $<0.05$ in the univariate analysis, as well as age and gender. Model 2 included the variables in Model 1 in addition to baseline LDL cholesterol, HbA1c and systolic blood pressure (SBP). A two-sided probability value of 
Table 2. Risk Factor Control in the Progressors and Nonprogressors

\begin{tabular}{|c|c|c|c|}
\hline & $\begin{array}{l}\text { Non-progressor } \\
\quad(n=73)\end{array}$ & $\begin{array}{c}\text { Progressor } \\
\quad(n=64)\end{array}$ & $p$-value \\
\hline \multicolumn{4}{|l|}{ Glycemic Profile } \\
\hline \multicolumn{4}{|l|}{ Fasting plasma glucose } \\
\hline Baseline (mg/dL) & $97.6 \pm 10.2$ & $97.6 \pm 12.1$ & 0.99 \\
\hline Follow-up $(\mathrm{mg} / \mathrm{dL})$ & $99.8 \pm 10.4$ & $99.7 \pm 13.3$ & 0.97 \\
\hline Percent change (\%) & $+2.3 \pm 10.9$ & $+3.6 \pm 17.4$ & 0.63 \\
\hline \multicolumn{4}{|l|}{ Postprandial glucose } \\
\hline Baseline (mg/dL) & $196.5 \pm 33.7$ & $200.7 \pm 35.5$ & 0.50 \\
\hline Follow-up (mg/dL) & $131.7 \pm 36.4$ & $136.3 \pm 33.9$ & 0.49 \\
\hline Percent change (\%) & $-30.9 \pm 16.6$ & $-34.9 \pm 12.4$ & 0.20 \\
\hline \multicolumn{4}{|l|}{ Fasting plasma insulin } \\
\hline Baseline (IU/L) & $7.2 \pm 4.0$ & $7.6 \pm 5.4$ & 0.69 \\
\hline Follow-up (IU/L) & $6.8 \pm 4.8$ & $8.0 \pm 6.7$ & 0.27 \\
\hline Percent change (\%) & $+2.8 \pm 45.4$ & $+17.3 \pm 69.2$ & 0.21 \\
\hline \multicolumn{4}{|c|}{ Postprandial plasma insulin } \\
\hline Baseline (IU/L) & $126.0 \pm 88.0$ & $99.9 \pm 58.6$ & 0.07 \\
\hline Follow-up (IU/L) & $65.3 \pm 56.6$ & $72.5 \pm 53.4$ & 0.50 \\
\hline Percent change (\%) & $-34.5 \pm 54.4$ & $-21.1 \pm 45.4$ & 0.19 \\
\hline \multicolumn{4}{|l|}{ HbAlc } \\
\hline Baseline (\%) & $5.4 \pm 0.4$ & $5.5 \pm 0.4$ & 0.41 \\
\hline Follow-up (\%) & $5.3 \pm 0.4$ & $5.4 \pm 0.3$ & 0.57 \\
\hline Absolute change & $-0.08 \pm 0.31$ & $-0.08 \pm 0.35$ & 0.98 \\
\hline \multicolumn{4}{|l|}{ Lipid Profile } \\
\hline \multicolumn{4}{|l|}{ total cholesterol } \\
\hline Baseline (mg/dL) & $186.5 \pm 37.0$ & $190.7 \pm 38.3$ & 0.54 \\
\hline Follow-up (mg/dL) & $170.2 \pm 29.4$ & $168.2 \pm 31.2$ & 0.71 \\
\hline Percent change (\%) & $-6.4 \pm 18.3$ & $-9.3 \pm 20.2$ & 0.41 \\
\hline \multicolumn{4}{|l|}{ triglyceride } \\
\hline Baseline (mg/dL) & $123.0(96.0,175.0)$ & $135.0(90.2,204.0)$ & 0.16 \\
\hline Follow-up (mg/dL) & $110.0(75.0,158.0)$ & $116.5(89.5,160.2)$ & 0.08 \\
\hline Percent change (\%) & $-5.8 \pm 49.5$ & $+11.2 \pm 80.5$ & 0.16 \\
\hline \multicolumn{4}{|l|}{ HDL-C } \\
\hline Baseline (mg/dL) & $42.4 \pm 10.8$ & $40.0 \pm 8.9$ & 0.19 \\
\hline Follow-up (mg/dL) & $48.9 \pm 11.4$ & $47.1 \pm 10.8$ & 0.40 \\
\hline Percent change (\%) & $+18.5 \pm 28.1$ & $+21.7 \pm 37.9$ & 0.60 \\
\hline \multicolumn{4}{|l|}{ LDL-C } \\
\hline Baseline (mg/dL) & $119.3 \pm 30.8$ & $124.3 \pm 33.2$ & 0.39 \\
\hline Follow-up (mg/dL) & $100.8 \pm 25.3$ & $96.9 \pm 24.1$ & 0.39 \\
\hline Percent change (\%) & $-10.9 \pm 27.3$ & $-17.1 \pm 26.4$ & 0.21 \\
\hline \multicolumn{4}{|l|}{ Blood Pressure } \\
\hline \multicolumn{4}{|l|}{ SBP } \\
\hline Baseline (mmHg) & $125.0 \pm 14.5$ & $120.3 \pm 12.6$ & 0.06 \\
\hline Follow-up (mmHg) & $124.4 \pm 16.6$ & $126.2 \pm 13.9$ & 0.52 \\
\hline Percent change (\%) & $-1.8 \pm 17.1$ & $+5.4 \pm 10.9$ & 0.007 \\
\hline \multicolumn{4}{|l|}{ DBP } \\
\hline Baseline (mmHg) & $69.4 \pm 9.3$ & $69.3 \pm 8.9$ & 0.94 \\
\hline Follow-up (mmHg) & $69.3 \pm 10.3$ & $71.5 \pm 10.3$ & 0.24 \\
\hline Percent change (\%) & $-0.7 \pm 20.7$ & $+4.0 \pm 14.9$ & 0.15 \\
\hline
\end{tabular}


(Cont Table 2)

\begin{tabular}{|c|c|c|c|}
\hline & $\begin{array}{l}\text { Non-progressor } \\
\quad(n=73)\end{array}$ & $\begin{array}{c}\text { Progressor } \\
(n=64)\end{array}$ & $p$-value \\
\hline \multicolumn{4}{|l|}{ Others } \\
\hline \multicolumn{4}{|l|}{ BMI } \\
\hline Baseline $\left(\mathrm{kg} / \mathrm{m}^{2}\right)$ & $24.1 \pm 2.8$ & $24.4 \pm 3.2$ & 0.61 \\
\hline Follow-up $\left(\mathrm{kg} / \mathrm{m}^{2}\right)$ & $23.7 \pm 3.1$ & $24.1 \pm 3.3$ & 0.51 \\
\hline Percent change (\%) & $-1.3 \pm 6.4$ & $-0.8 \pm 7.6$ & 0.67 \\
\hline \multicolumn{4}{|l|}{ Adiponectin } \\
\hline Baseline (mg/L) & $7.3 \pm 4.0$ & $7.3 \pm 3.1$ & 0.96 \\
\hline Follow-up (mg/L) & $8.7 \pm 3.5$ & $8.9 \pm 3.9$ & 0.75 \\
\hline Percent change (\%) & $+26.6 \pm 34.6$ & $+23.5 \pm 45.4$ & 0.71 \\
\hline \multicolumn{4}{|l|}{$\mathrm{Hs}$-CRP } \\
\hline Baseline $(\mathrm{mg} / \mathrm{dL})^{*}$ & $3.9(1.4,9.1)$ & $2.8(0.7,7.5)$ & 0.08 \\
\hline Follow-up $(\mathrm{mg} / \mathrm{dL})^{*}$ & $0.7(0.3,2.6)$ & $0.5(0.2,1.4)$ & 0.91 \\
\hline Percent change (\%) & $-81.1 \pm 32.4$ & $-82.1 \pm 28.6$ & 0.90 \\
\hline
\end{tabular}

The values are presented as the mean $\pm \mathrm{SD}$ or median (interquartile range).

$\mathrm{BMI}=$ body mass index, $\mathrm{DBP}=$ diastolic blood pressure, $\mathrm{HbA1c}=$ glycated hemoglobin, HDL-C $=$ high-density lipoprotein cholesterol, $\mathrm{HMW}=$ high molecular weight, $\mathrm{Hs}-\mathrm{CRP}=$ high-sensitivity $\mathrm{c}$-reactive protein, LDL-C =low-density lipoprotein cholesterol, SBP = systolic blood pressure

*: Median (interquartile range)

$<0.05$ was considered to be statistically significant. All analyses were performed using the JMP software program, version 8.0.2 (SAS Institute, Cary, North Carolina).

\section{Results}

\section{Clinical Demographics of the Study Subjects}

In the current study, $46 \%(n=64)$ of the study participants exhibited substantial atheroma progression at one year despite improvements in glycemic abnormalities. The clinical characteristics of the progressors and non-progressors are summarized in Table 1. The study subjects were predominantly men $(86.0 \%)$, with a high prevalence of hypertension $(85.9 \%)$ and dyslipidemia (66.6\%). The use of various antiatherosclerotic medications and the assigned antidiabetic therapy at baseline and one year were identical between the two groups.

\section{Risk Factor Control}

The degree of risk factor control is summarized in Table 2. At baseline, the values of each risk factor were comparable. At one year, despite the use of various antihypertensive therapies (beta-blockers: 63.1\%, calcium channel blockers: $33.9 \%$, angiotensin II coenzyme inhibitors: $33.9 \%$, angiotensin II receptor blockers: $39.2 \%)$, the progressors exhibited increased SBP values (percent change: $+5.4 \pm 10.9 \%$ vs. $-1.8 \pm$
$17.1 \%, p=0.007)$. The glycemic and lipid profiles and other biomarkers were similar between the two groups.

\section{Measurements of the Atheroma Burden on Angiography}

The measurements of the atheroma burden at baseline and on the serial evaluations are summarized in Table 3. The progressors demonstrated less extensive disease at baseline, as reflected by a shorter TLL $(10.1 \pm 9.8 \mathrm{~mm}$ vs. $14.4 \pm 11.2 \mathrm{~mm}, p=0.01)$. Predictably, profound atheroma progression was observed in the progressors, with a greater absolute $(+4.3 \pm 2.8 \mathrm{~mm}$ vs. $-2.1 \pm 2.7 \mathrm{~mm}, p<0.0001)$ and percent change in TLL $(+41.0 \pm 39.9 \%$ vs. $-15.9 \pm 16.8 \%, p<0.0001)$.

\section{Independent Predictors of Disease Progression Despite Optimal Glucose Control}

The results of the univariate and multivariate analyses of the predictors of disease progression are summarized in Table 4. The multivariate analysis demonstrated that an increased SBP $(p=0.001)$, treatment without statins at follow-up $(p=0.03)$ and the baseline TLL $(p=0.005)$ were associated with disease progression (Table 4, Model 1). In addition, even after adjusting for age, gender, baseline LDL-cholesterol (LDL-C), HbA1c and SBP, the analysis continued to show that independently associated risk factors for atheroma progression in early-stage diabetic 
Table 3. Measurements of the Atheroma Burden in the Progressors and Nonprogressors

\begin{tabular}{lccc}
\hline & $\begin{array}{c}\text { Non-progressor } \\
(n=73)\end{array}$ & $\begin{array}{c}\text { Progressor } \\
(n=64)\end{array}$ & $p$-value \\
\hline Baseline TLL $(\mathrm{mm})$ & $14.4 \pm 11.2$ & $10.1 \pm 9.8$ & 0.01 \\
One-year TLL $(\mathrm{mm})$ & $12.2 \pm 10.3$ & $15.0 \pm 13.7$ & 0.21 \\
Absolute change from baseline $(\mathrm{mm})$ & $-2.1 \pm 2.7$ & $+4.3 \pm 2.8$ & $<0.0001$ \\
\% change from baseline & $-15.9 \pm 16.8$ & $41.0 \pm 39.9$ & $<0.0001$ \\
\hline
\end{tabular}

$\mathrm{TLL}=$ total lesion length

patients with optimal glucose control included an increased SBP $(p=0.006)$, treatment without statins at follow-up $(p=0.03)$ and the baseline TLL $(p=0.007)$ (Table 4, Model 2).

\section{Discussion}

The findings of the DIANA study illustrated the importance of achieving glycemic control for preventing atheroma progression in early-stage diabetic patients with $\mathrm{CAD}^{13}$. However, the current subanalysis demonstrated that $46 \%$ of the patients with an improved glycemic status continued to exhibit disease progression. Furthermore, the patients with greater increases in SBP and those who did not receive statin therapy were more likely to demonstrate disease progression. Our findings suggest the importance of providing blood pressure treatment and statin therapy, in addition to glucose-lowering treatment, for preventing the progression of coronary atherosclerosis in earlystage diabetic patients.

Previous studies have reported the benefits of pharmacological and lifestyle interventions in improving the glycemic status and/or future outcomes in patients with prediabetes or newly diagnosed diabetes ${ }^{16-18)}$. Additionally, the DIANA study demonstrated the antiatherosclerotic efficacy of early glucose modification therapy in patients with early-stage diabetes ${ }^{13)}$. However, there is a paucity of data regarding earlystage diabetic patients who subsequently experience cardiovascular events or progression of atherosclerotic disease despite exhibiting a well-controlled glycemic status.

In the current analysis, achieving improvements in abnormal glycemic tolerance did not halt the progression of atheroma in $46 \%$ of the study subjects in the DIANA study. Since residual risk factors contribute to atheroma progression, our observations support the concept that coronary atherosclerosis is a multifactorial disease that requires a therapeutic approach to modify global risks rather than individual risk factors in order to prevent disease progression. These findings are supported by the results of previous clinical studies of advanced diabetic patients. The Steno-II study demonstrated the benefits of multifactorial intensified intervention for preventing future cardiovascular events ${ }^{19)}$. The PERISCOPE (Comparison of Pioglitazone Versus Glimepiride on Progression of Coronary Atherosclerosis in Patients With Type 2 Diabetes) trial illustrated the antiatherosclerotic benefits of pioglitazone in modifying glycemic as well as non-glycemic factors ${ }^{20)}$. In addition, the use of strategies to control multiple risks is crucial for preventing cardiovascular disease, even among Japanese diabetic patients with a relatively lower incidence of $\mathrm{CAD}^{21)}$. As diabetes promotes the development of atherosclerosis in the setting of profound metabolic abnormalities, including hypertension, dyslipidemia and increased systemic inflammation $^{22-25)}$, the current results highlight the significance of global risk management, even earlystage diabetic patients, for preventing disease progression.

Our findings indicate that relatively a small increase in SBP is associated with substantial atheroma progression. Interestingly, although the observed small rise in SBP remained within the normal blood pressure range, the progression of coronary atherosclerosis was substantial. Considering that atherosclerotic plaque accumulates and vascular risks begin to increase when the blood pressure exceeds $115 / 75 \mathrm{mmHg}^{26,27)}$, obtaining lower blood pressure values is crucial for modifying the progressive nature of the disease in early-stage diabetics. Further investigation to clarify the optimal SBP goal in this population is required.

Large randomized clinical trials have consistently demonstrated the antiatherosclerotic benefits of statins in various subjects, including diabetic patients ${ }^{28-31)}$. The current study also highlights the importance of statin use in early-stage diabetics with CAD. Inflammation and oxidative stress are believed to be drivers contributing to disease progression in diabetic patients ${ }^{32,33)}$. Given that statins modulate pathways of inflammation and oxidation ${ }^{34,35)}$, statin-mediated pleiotropic effects may result in reduced progression of coronary 
Table 4. Clinical Predictors of Atheroma Progression

(a) Univariate Analysis

\begin{tabular}{llc} 
& Odds ratio $(95 \%$ CI) & $p$-value \\
\hline Age & $1.017(0.979-1.057)$ & 0.24 \\
Female & $2.401(0.825-7.992)$ & 0.11 \\
diagnosis of IGT at baseline & $1.364(0.663-2.824)$ & 0.39 \\
$\%$ change in Fasting plasma glucose & $0.993(0.967-1.019)$ & 0.62 \\
\% change in Postprandial glucose & $1.001(0.976-1.026)$ & 0.91 \\
$\%$ change in Fasting plasma insulin & $0.995(0.988-1.002)$ & 0.20 \\
$\%$ change in Postprandial plasma insulin & $0.994(0.985-1.002)$ & 0.18 \\
change in HbAlc & $0.992(0.325-3.010)$ & 0.98 \\
$\%$ change in total cholesterol & $1.007(0.989-1.027)$ & 0.41 \\
$\%$ change in triglyceride & $0.995(0.989-1.001)$ & 0.15 \\
$\%$ change in HDL cholesterol & $0.997(0.985-1.011)$ & 0.70 \\
$\%$ change in LDL cholesterol & $1.008(0.995-1.023)$ & 0.20 \\
$\%$ change in SBP & $1.067(1.026-1.136)$ & 0.003 \\
$\%$ change in DBP & $0.984(0.962-1.005)$ & 0.14 \\
$\%$ change in BMI & $0.988(0.937-1.041)$ & 0.66 \\
$\%$ change in adiponectin & $1.002(0.991-1.013)$ & 0.71 \\
Statin use at one year & $0.999(0.998-1.001)$ & 0.29 \\
Beta-blocker at one year & $0.533(0.198-0.941)$ & 0.03 \\
Calcium channel blocker at one year & $1.425(0.458-2.811)$ & 0.26 \\
ACE-I at one year & $0.973(0.453-2.095)$ & 0.94 \\
ARB at one year & $0.556(0.243-1.245)$ & 0.15 \\
Life-style intervention & $1.595(0.772-3.334)$ & 0.20 \\
Baseline TLL & $0.724(0.461-1.593)$ & 0.49 \\
\hline A & $0.614(0.218-0.905)$ & 0.001 \\
\hline
\end{tabular}

ACE- $\mathrm{I}=$ angiotensin II coenzyme inhibitor, $\mathrm{ARB}=$ angiotensin II receptor blocker, $\mathrm{DBP}=$ diastolic blood pressure, $\mathrm{HbA1c}=$ glycated hemoglobin, $\mathrm{HDL}=$ high-density lipoprotein, hs-CRP $=$ high-sensitivity $\mathrm{c}$-reactive protein, $\mathrm{IGT}=$ impaired glucose tolerance, $\mathrm{LDL}=$ low-density lipoprotein, $\mathrm{SBP}=$ systolic blood pressure, $\mathrm{TLL}=$ total lesion length

(b) Multivariate Analysis

Model $1^{*}$

\begin{tabular}{lll} 
& Odds ratio $(95 \%$ CI) & $p$-value \\
\hline Age & $1.010(0.969-1.052)$ & 0.63 \\
Female & $2.706(0.845-10.027)$ & 0.09 \\
\% change in SBP & $1.053(1.019-1.087)$ & 0.001 \\
Statin use at one year & $0.357(0.120-0.977)$ & 0.03 \\
Baseline TLL & $0.738(0.222-0.933)$ & 0.005 \\
\hline
\end{tabular}

* Model 1 includes covariates with a $p$-value of $<0.05$ in the univariate analysis, as well as age and gender.

Model $2^{\#}$

\begin{tabular}{llc} 
& Odds ratio $(95 \%$ CI) & $p$-value \\
\hline Age & $1.007(0.964-1.053)$ & 0.72 \\
Female & $1.572(0.318-6.083)$ & 0.43 \\
Baseline LDL cholesterol & $0.993(0.980-1.006)$ & 0.33 \\
Baseline HbA1c & $0.656(0.243-1.728)$ & 0.39 \\
Baseline SBP & $1.014(0.981-1.051)$ & 0.39 \\
\% change in SBP & $1.046(1.012-1.083)$ & 0.006 \\
Statin use at one year & $0.417(0.139-0.936)$ & 0.03 \\
Baseline TLL & $0.754(0.231-0.952)$ & 0.007 \\
\hline
\end{tabular}

\# Model 2 includes the variables in Model 1 in addition to baseline LDL cholesterol, HbA1c and SBP.

$\mathrm{HbA1c}=$ glycated hemoglobin, $\mathrm{LDL}=$ low-density lipoprotein, $\mathrm{SBP}=$ systolic blood pressure, $\mathrm{TLL}=$ total lesion length 
atherosclerosis in early-stage diabetics with CAD.

The presence of ongoing disease progression despite the achievement of an LDL-C level below 100 $\mathrm{mg} / \mathrm{dL}$ in the progressors indicates the need for stricter control of LDL-C, even in early-stage diabetics with CAD. Recent studies have demonstrated that coronary atherosclerosis regresses if a very low level of LDL-C is achieved with potent statin therapy ${ }^{36,37)}$. As statin use was found to be a significant factor associated with reduced disease progression in early-stage diabetics with CAD in this study, the optimal dose of statin therapy and target level of LDL-C in such patients should be clarified in future studies.

A number of caveats regarding the present study should be noted. This post hoc analysis evaluated observational data generated from the DIANA study. The study population was relatively small, and the study lacked sufficient power to examine the association between plaque progression and outcomes. As all patients had a diagnosis of CAD, it is unknown if the current findings can be translated to the setting of primary prevention. However, the observation that asymptomatic diabetic patients have prospective cardiovascular risks comparable to those of nondiabetic survivors of myocardial infarction ${ }^{38)}$ suggests that the underlying disease is aggressive, even among patients who have yet to receive clinical attention. Coronary angiography has limitations in evaluating plaque composition and vessel remodeling. While the features observed on this modality have been reported to be associated with disease progression, plaque vulnerability and cardiovascular events ${ }^{39}, 40$ ), it remains to be determined whether progressors are different from non-progressors with regard to plaque composition and vessel remodeling. Given that recent intravascular imaging modalities enable clinicians to visualize morphology, it would be interesting to investigate the characteristics of plaque in progressors and non-progressors using serial intravascular imaging.

In summary, despite exhibiting favorable control of their glycemic status, $46 \%$ of the early-stage diabetic patients with CAD evaluated in this study continued to demonstrate atheroma progression. Additionally, the greatest antiatherosclerotic impact is likely to be achieved under SBP control and treatment with statins. These findings intensify the clinical need to adopt a therapeutic strategy for modifying multiple risk factors in order to halt disease progression in early-stage diabetic patients with CAD.

\section{Source of Funding}

The DIANA study was performed under spon- sorship of the Japan Cardiovascular Research Foundation. The organization had no role in the study design, data collection, data analysis, data interpretation or writing of the report.

\section{Acknowledgments}

We would like to acknowledge Mrs. Hiromi Maeda for her excellent secretarial assistance and $\mathrm{Mr}$. Izuru Nakasone for his cooperation. In addition, we would like to acknowledge the sponsorship of the Japan Cardiovascular Research Foundation.

\section{Conflicts of Interest}

None.

\section{Abbreviations}

$\mathrm{CAD}=$ coronary artery disease, $\mathrm{DIANA}=\mathrm{DIA}-$ betes and diffuse coronary NArrowing, $\mathrm{DM}=$ diabetes mellitus, $\mathrm{HbA} 1 \mathrm{c}=$ glycosylated hemoglobin, $\mathrm{HDL}=$ high-density lipoprotein, IGT=impaired glucose tolerance, $\mathrm{LDL}=$ low-density lipoprotein, OGTT $=$ oral glucose tolerance test, $\mathrm{SBP}=$ systolic blood pressure, $\mathrm{TLL}=$ total lesion length, $\mathrm{QCA}=$ quantitative coronary angiography.

\section{References}

1) Fox CS, Coady S, Sorlie PD, D’Agostino RB Sr, Pencina MJ, Vasan RS, Meigs JB, Levy D, Savage PJ: Increasing cardiovascular disease burden due to diabetes mellitus: the Framingham Heart Study. Circulation, 2007; 115: 15441550

2) Nicholls SJ, Tuzcu EM, Kalidindi S, Wolski K, Moon KW, Sipahi I, Schoenhagen P, Nissen SE: Effect of diabetes on progression of coronary atherosclerosis and arterial remodeling: a pooled analysis of 5 intravascular ultrasound trials. J Am Coll Cardiol, 2008; 52: 255-262

3) Huxley R, Barzi F, Woodward M: Excess risk of fatal coronary heart disease associated with diabetes in men and women: meta-analysis of 37 prospective cohort studies. BMJ, 2006; 332: 73-78

4) Ho JE, Paultre F, Mosca L; Women's Pooling Project: Is diabetes mellitus a cardiovascular disease risk equivalent for fatal stroke in women? Data from the Women's Pooling Project. Stroke, 2003; 34: 2812-2816

5) Stamler J, Vaccaro O, Neaton JD, Wentworth D: Diabetes, other risk factors, and 12-yr cardiovascular mortality for men screened in the Multiple Risk Factor Intervention Trial. Diabetes Care, 1993; 16: 434-444

6) The DECODE Study Group on behalf of the European Diabetes Epidemiology Group: Is the current definition for diabetes relevant to mortality risk from all causes and cardiovascular and non cardiovascular diseases? Diabetes 
Care, 2003; 26: 688-696

7) Tominaga M, Eguchi H, Manaka H, Igarashi K, Kato T, Sekikawa A: Impaired glucose tolerance is a risk factor for cardiovascular disease, but not impaired fasting glucose. the Funagata Diabetes Study. Diabetes Care, 1999; 22: 920-924

8) Bartnik M, Malmberg K, Norhammar A, Tenerz A, Ohrvik J, Ryden L: Newly detected abnormal glucose tolerance: an important predictor of long- term outcome after myocardial infarction. Eur Heart J, 2004; 25: 19901997

9) Sourij H, Saely CH, Schmid F, Zweiker R, Marte T, Wascher TC, Drexel H: Post-challenge hyperglycaemia is strongly associated with future macrovascular events and total mortality in angiographied coronary patients. Eur Heart J, 2010; 31: 1583-1590

10) Kim TN, Kim S, Yang SJ, Yoo HJ, Seo JA, Kim SG, Kim $\mathrm{NH}$, Baik SH, Choi DS, Choi KM: Vascular inflammation in patients with impaired glucose tolerance and type 2 diabetes: analysis with $18 \mathrm{~F}$-fluorodeoxyglucose positron emission tomography. Circ Cardiovasc Imaging, 2010; 3: $142-148$

11) Faeh D, William J, Yerly P, Paccaud F, Bovet P: Diabetes and pre-diabetes are associated with cardiovascular risk factors and carotid/femoral intima-media thickness independently of markers of insulin resistance and adiposity. Cardiovasc Diabetol, 2007; 6: 32

12) Kataoka Y, Yasuda S, Morii I, Otsuka Y, Kawamura A, Miyazaki S: Quantitative coronary angiographic studies of patients with angina pectoris and impaired glucose tolerance. Diabetes Care, 2005; 28: 2217-2222

13) Kataoka Y, Yasuda S, Miyamoto Y, Sase K, Kosuge M, Kimura K, Yoshimasa Y, Miyazaki S; DIANA study investigators: Effects of voglibose and nateglinide on glycemic status and coronary atherosclerosis in early-stage diabetic patients. Circ J, 2012; 76: 712-720

14) Kataoka Y, Yasuda S, Morii I, Kawamura A, Miyazaki S: Improved long-term prognosis of elderly women in the era of sirolimus-eluting stents. Circ J, 2009; 73: 12191227

15) Alberti KG, Zimmet PZ: Definition, diagnosis and classification of diabetes mellitus and its complications. Part 1: diagnosis and classification of diabetes mellitus provisional report of a WHO consultation. Diabet Med, 1998; 115: 539-553

16) Tuomilehto J, Lindström J, Eriksson JG, Valle TT, Hämäläinen $\mathrm{H}$, Ilanne-Parikka $\mathrm{P}$, Keinänen-Kiukaanniemi S, Laakso M, Louheranta A, Rastas M, Salminen V, Uusitupa M; Finnish Diabetes Prevention Study Group: Prevention of type 2 diabetes mellitus by changes in lifestyle among subjects with impaired glucose tolerance. $\mathrm{N}$ Engl J Med, 2001; 344: 1343-1350

17) Chiasson JL, Josse RG, Gomis R, Hanefeld M, Karasik A, Laakso M; STOP-NIDDM Trial Research Group: Acarbose treatment and the risk of cardiovascular disease and hypertension in patients with impaired glucose tolerance: the STOP-NIDDM trial. JAMA, 2003; 290: 486-494

18) DREAM (Diabetes REduction Assessment with ramipril and rosiglitazone Medication) Trial Investigators, Gerstein HC, Yusuf S, Bosch J, Pogue J, Sheridan P, Dinccag N,
Hanefeld M, Hoogwerf B, Laakso M, Mohan V, Shaw J, Zinman B, Holman RR: Effect of rosiglitazone on the frequency of diabetes in patients with impaired glucose tolerance or impaired fasting glucose: a randomised controlled trial. Lancet, 2006; 368: 1096-1105

19) Gaede P, Vedel P, Larsen N, Jensen GV, Parving HH, Pedersen $\mathrm{O}$ : Multifactorial intervention and cardiovascular disease in patients with type 2 diabetes. N Engl J Med, 2003; 348: 383-393

20) Nissen SE, Nicholls SJ, Wolski K, Nesto R, Kupfer S, Perez A, Jure H, De Larochellière R, Staniloae CS, Mavromatis K, Saw J, Hu B, Lincoff AM, Tuzcu EM; PERISCOPE Investigators: Comparison of pioglitazone vs glimepiride on progression of coronary atherosclerosis in patients with type 2 diabetes: the PERISCOPE randomized controlled trial. JAMA, 2008; 299: 1561-1573

21) Teramoto $T$, Sasaki J, Ishibashi $S$, Birou $S$, Daida $H$, Dohi $S$, Egusa G, Hiro T, Hirobe $K$, Iida M, Kihara S, Kinoshita M, Maruyama C, Ohta T, Okamura T, Yamashita S, Yokode M, Yokote K; Japan Atherosclerosis Society (JAS). Guidelines for the diagnosis and prevention of atherosclerotic cardiovascular disease in Japan 2012. J Atheroscler Thromb, 2013; 20: 603-615

22) Krauss RM: Lipids and lipoproteins in patients with type 2 diabetes. Diabetes Care, 2004; 27: 1496-1504

23) Boden G, Laakso M: Lipids and glucose in type 2 diabetes: what is the cause and effect? Diabetes Care, 2004; 27: 2253-2259

24) Ginsberg HN, Zhang YL, Hernandez-Ono A: Regulation of plasma triglycerides in insulin resistance and diabetes. Arch Med Res, 2005; 36: 232-240

25) Garvey WT, Kwon S, Zheng D, Shaughnessy S, Wallace P, Hutto A, Garvey WT, Kwon S, Zheng D, Shaughnessy S, Wallace P, Hutto A, Pugh K, Jenkins AJ, Klein RL, Liao Y: Effects of insulin resistance and type 2 diabetes on lipoprotein subclass particle size and concentration determined by nuclear magnetic resonance. Diabetes, 2003; 52: 453-462

26) Sipahi I, Tuzcu EM, Schoenhagen P, Wolski KE, Nicholls SJ, Balog C, Crowe TD, Nissen SE: Effects of normal, pre-hypertensive, and hypertensive blood pressure levels on progression of coronary atherosclerosis. J Am Coll Cardiol, 2006; 48: 833-838

27) Lewington S, Clarke R, Qizilbash N, Peto R, Collins R, for the Prospective Studies Collaboration: Age-specific relevance of usual blood pressure to vascular mortality: a meta-analysis of individual data for one million adults in 61 prospective studies. Lancet, 2002; 360: 1903-1913

28) Randomised trial of cholesterol lowering in 4444 patients with coronary heart disease: the Scandinavian Simvastatin Survival Study (4S). Lancet, 1994; 344: 1381-1389

29) Heart Protection Study Collaborative Group: MRC/BHF Heart Protection Study of cholesterol lowering with simvastatin in 20,536 high-risk individuals: a randomised placebo-controlled trial. Lancet, 2002; 360: 7-22

30) Downs JR, Clearfield M, Weis S, Whitney E, Shapiro DR, Beere PA, Angendorfer A, Stein EA, Kruyer W, Gotto AM Jr: Primary prevention of acute coronary events with lovastatin in men and women with average cholesterol levels: results of AFcaps/Texcaps. AirForce/ 
Texas Coronary Atherosclerosis Prevention Study. JAMA, 1998; 279: 1615-1622

31) Sacks FM, Pfeffer MA, Moye LA, Rouleau JL, Rutherford JD, Cole TG, Brown L, Warnica JW, Arnold JM, Wun CC, Davis BR, Braunwald E: Cholesterol and Recurrent Events Trial investigators: The effect of pravastatin on coronary events after myocardial infarction in patients with average cholesterol levels. N Engl J Med, 1996; 335: 1001-1009

32) Haffner SM: Insulin resistance, inflammation, and the prediabetic state. Am J Cardiol, 2003; 92: 18J-26J

33) Mehta JL, Rasouli N, Sinha AK, Molavi B: Oxidative stress in diabetes: a mechanistic overview of its effects on atherogenesis and myocardial dysfunction. Int J Biochem Cell Biol, 2006; 38: 794-803

34) Spite M, Serhan CN: Novel lipid mediators promote resolution of acute inflammation: impact of aspirin and statins. Circ Res, 2010; 107: 1170-1184

35) Mason RP, Walter MF, Jacob RF: Effects of HMG-CoA reductase inhibitors on endothelial function: role of microdomains and oxidative stress. Circulation, 2004; 109: II34-II41

36) Nissen SE, Nicholls SJ, Sipahi I, Libby P, Raichlen JS, Ballantyne CM, Davignon J, Erbel R, Fruchart JC, Tardif JC, Schoenhagen P, Crowe T, Cain V, Wolski K, Goormastic M, Tuzcu EM; ASTEROID Investigators: Effect of very high-intensity statin therapy on regression of coronary atherosclerosis: the ASTEROID trial. JAMA, 2006; 295: 1556-1565

37) Nicholls SJ, Ballantyne CM, Barter PJ, Chapman MJ, Erbel RM, Libby P, Raichlen JS, Uno K, Borgman M, Wolski K, Nissen SE: Effect of two intensive statin regimens on progression of coronary disease. N Engl J Med, 2011; 365: 2078-2087

38) Haffner SM, Lehto S, Ronnemaa T, Pyorala K, Laakso M: Mortality from coronary heart disease in subjects with type 2 diabetes and in nondiabetic subjects with and without prior myocardial infarction. N Engl J Med, 1998; 339: 229-234

39) Takeuchi H, Morino Y, Matsukage T, Masuda N, Kawamura Y, Kasai S, Hashida T, Fujibayashi D, Tanabe T, Ikari Y: Impact of vascular remodeling on the coronary plaque compositions: an investigation with in vivo tissue characterization using integrated backscatter-intravascular ultrasound. Atherosclerosis, 2009; 202: 476-482

40) Stone GW, Maehara A, Lansky AJ, de Bruyne B, Cristea E, Mintz GS, Mehran R, McPherson J, Farhat N, Marso SP, Parise H, Templin B, White R, Zhang Z, Serruys PW; PROSPECT Investigators A prospective natural-history study of coronary atherosclerosis. N Engl J Med, 2011; 364: $226-235$ 